\title{
The new prescription: industrial injuries benefits for smokers?
}

\author{
Anthony Seaton
}

Nationalisation of the coal industry by the 1945 Labour Government provided Britain with a unique opportunity for preventing the disablement of coal miners. At that time several thousand miners received disability benefits each year for pneumoconiosis in South Wales alone, and the Medical Research Council had started an important series of investigations into the relationships between dust exposure and disease. ${ }^{12}$ The late Dr John Rogan, Chief Medical Officer of the National Coal Board, with extraordinary far sightedness set up the Pneumoconiosis Field Research which ultimately studied the dust exposure, symptoms, chest radiographs, and lung function of some $50000 \mathrm{~min}-$ ers over nearly 30 years. $^{3}$ This research was planned to answer the questions "How much and what kinds of dust cause pneumoconiosis, and what dust concentrations need to be maintained if miners are not to be disabled by the dust that they breathe?" The National Coal Board embarked on a massively costly programme of research into dust control in mines alongside its medical research and, in full consultation with the mining unions, progressively implemented the research results into its practical management of the pneumoconiosis problem. As an example of enlightened management in dealing with work related ill health, this endeavour is unparalleled. The pneumoconiosis statistics tell the story, the disease having largely been eliminated.

Implicit in Dr Rogan's original question was the understanding that disease other than pneumoconiosis might disable coal miners. This proved to be the case, the research demonstrating impressive evidence of a relationship between dust exposure and airways obstruction and, in accompanying pathological studies, centriacinar emphysema (in the presence of some evidence also of fibrotic nodular pneumoconiosis). This led me to suggest to the Industrial Injuries Advisory Council (IIAC) that in certain circumstances chronic airways obstruction should be regarded as an occupational hazard of coal miners, appropriate for prescription. ${ }^{4}$ At first my arguments were not accepted, but further evidence from the Coal Board's research eventually persuaded the IIAC and the disease was prescribed in 1992 .

Central to my evidence was discussion of the problem posed by the frequency of the disease in miners, as in nonminers, as a consequence of smoking. This habit was and is commonplace among miners and is, of course, the main reason most develop airways obstruction. Epidemiologically, in any population of miners rather more will develop disease than would be the case in a non-dust exposed population because of the additive effects of the two causes of alveolar and bronchiolar inflammation. How then should these two causes be differentiated in the individual in order to reduce the likelihood of benefits being paid for smoking and increase the likelihood of compensation for those in whom dust exposure had played a clinically significant role? In my view at the time this enigma could be solved by using an index of dust exposure, either based on work records or on a surrogate measure. The former was impracticable, the variations in historical dust concentrations and toxicity between mines making a simple index of years worked misleading. However, the latter was relatively straightforward-evidence of dust retention on the chest radiograph relates well to dust exposure-and liberalisation of the criteria from category 2 pneumoconiosis to category $1 / 1$ opacities, either rounded or irregular, judged by the ILO standard films was, in my view, a reasonable means of separating those in whom dust exposure was likely to have made a significant contribution from those in whom it had probably not. ${ }^{5}$ Of course it would be unfair to some and allow unjust compensation to others, as will all schemes that arbitrarily dichotomise a continuum, but at least it was semi-objective, assuming film readers were appropriately trained and experienced in the use of the standard ILO films. I argued strongly against the use of a qualifying period since, as stated above, time underground does not relate to risk of disease, the concentrations and types of dust being the critical factors. The IIAC did not accept my advice on this, and originally chose to use both radiological and time criteria.

After further representations from interested parties, but not myself, IIAC reconsidered these criteria and recommended new ones to the Secretary of State in 1996; these were accepted by the Government. These new criteria for certification of the prescribed disease, chronic bronchitis and emphysema in coal miners, are as follows ${ }^{6}:$ (1) work in an underground coal mine for at least 20 years without the need for discount for periods of sickness absence; (2) a forced expiratory volume in one second at least one litre below the predicted value or less than one litre in total; (3) no need for radiographic evidence of coal dust retention.

The reasons given by IIAC for its change in criteria are based on what it calls important new evidence. One study in Nottinghamshire showed that the risk of airways disease in miners was increased in the absence of "pneumoconiosis" as defined by one reader. ${ }^{7}$ It failed to take account of category 1 irregular changes, gave no indication of the reliability of the radiographic readings, and showed an important interaction between age and mining such that mining exposure ceased to show an effect after the age of 60 (perhaps attributable to a healthy survivor effect). It had no measurements of dust exposure, but the findings are unexceptionable and simply support the conclusions of much larger and more detailed studies which have shown that the more coal dust to which a miner has been exposed, the greater his risk of a reduced $\mathrm{FEV}_{1}$ regardless of the presence or absence of pneumoconiosis. It has never been claimed that simple pneumoconiosis itself causes airways obstruction, simply that the two responses are separate effects of the same dust. Of course some miners have one without the other, but the huge majority of miners with a low $\mathrm{FEV}_{1}$ without any evidence of dust retention on their radiograph are likely to have airway obstruction predominantly due to smoking, while in those with such changes it is much more likely that the dust exposure has made a contribution.

The other study quoted showed that excess mortality from chronic bronchitis and emphysema in miners does not correlate geographically with death rates from pneumoconiosis. $^{8}$ This is taken to provide evidence that different types of dust have different pathological effects in causing these two diseases, a conclusion that flies in the face of all the evidence from the Pneumoconiosis Field Research. The finding of this study is hardly surprising since doctors certifying the cause of death in miners dying of lung disease have had different patterns of diagnosis; in 
areas where pneumoconiosis is historically common, such as South Wales, they preferentially write "pneumoconiosis", whereas in other areas they prefer "chronic bronchitis". In either case the cause is the same since death from pneumoconiosis (that is, massive fibrosis since simple pneumoconiosis per se causes no functional impairment) since the 1970s has been vanishingly rare. There are, in fact, regional differences in airway responses to coal dust exposure as there are in pneumoconiosis rates, and these relate to the toxicity of the dust. These were shown in the last publications from the Field Research. ${ }^{9}{ }^{10}$ In a study of miners and ex-miners clear relationships were shown between dust exposure and $\mathrm{FEV}_{1}$ in South Wales but no longer in collieries in Yorkshire and the North-east of England when the strong association with age was taken into account, which suggests that dust control measures were already beginning to have an impact on airway disease.

It may not be generally realised how much effort the nationalised coal industry put into preventing disablement of its workers. The NCB and subsequently British Coal led the world not only in medical research into relationships between dust exposure and disease but also in dust control and dust measurement research, and the industry's senior managers, guided by their medical and scientific services, always paid great attention to the pneumoconiosis statistics as evidence of the efficacy of their dust control measures. One hopes that, now the coal mines are in private hands, they will continue to do so. What will they have to go on? Because of the rundown of the industry and the age structure of the workforce, there will be few new cases of certified pneumoconiosis for many years unless there are dramatic deteriorations in dust control. As miners will continue to smoke, however, there will continue to be certifications for airways obstruction, and these will occur no matter what steps the industry takes to reduce dust. Even if dust concentrations were reduced to a theoretical zero, 20 years' service and smoking would automatically qualify a disabled miner for compensation for an "occupational disease". The industry does not now have the opportunity of preventing "coal dust disease" except by preventing smokers from working in mines or by preventing men working for as long as 20 years. The latter provides an obvious means of reducing the figures since a mine owner needs only to institute a programme of spirometric tests and to retire on the grounds of ill health anyone who shows early evidence of a reduction in $\mathrm{FEV}_{1}$ before the 20 year period is achieved. While this may seem a not unreasonable means of preventive medicine, it should be remembered that the first principle of prevention is to eliminate or reduce exposure to the cause. Now radiological dust reten- tion is off the agenda, the immediate pressure is off the mine owners to continue their programme of progressive dust reduction below the legal standard.

In my view there is no scientific logic in the 20 year criterion. The only reasonably justifiable criterion of dust exposure in the absence of records of measured exposure remains the chest radiograph, especially the presence of small irregular shadows, category $1 / 1$ or greater. There was no real scientific justification for the change in prescription criteria which will increase the amount of money being paid out to compensate smokers and which will pose a preventive problem for the coal industry that it could solve to the economic, or ignore to the health, disadvantage of today's miners. I now anticipate that the argument will shift to the justice of the 20 year criterion and expect pressure to be brought to bear on IIAC to relax it to, say, 10 years. Or why not five years? Or one? These arguments will persist as long as there is a system of state benefits for diseases acquired at work separate from and additional to the rest of the Social Security system. The difference in benefits for coal miners and, say, smoking steel workers or welders with chronic airways disease illustrates the need for a radical review of the whole system. There is greater justice in a system of equal compensation for equal disability however acquired, leaving it to the Health and Safety Executive to ensure that the Heath and Safety at Work Act is effective in preventing industrial disease.

ANTHONY SEATON

Department of Environmental and

Occupational Medicine,

University Medical School,

Foresterhill, Aberdeen AB9 2ZD

1 Fletcher CM. Pneumoconiosis of coal-miners. BMf 1948;1:1015-22; 1065-74.

2 Hart Pd'A, Aslett EA. Chronic pulmonary disease in South Wales coalminers. 1 Medical studies. MRC Report Seies No 243. London: HMSO, 1942.

3 Fay JWJ. The National Coal Board's pneumoconiosis field research. Nature

4 Seaton A. Coalmining, emphysema and compensation. Br f Ind Med 1990; 47:433-5

5 Collins HPR, Dick JA, Bennett JG, et al. Irregularly shaped small shadows on chest radiographs, dust exposure and lung function in coalworkers' pneumoconiosis. Br F Ind Med 1988;45:43-55.

6 Department of Social Security. Chronic bronchitis and emphysema. London: HMSO, 1996.

7 Lewis S, Bennett J, Richards K, et al. A cross-sectional study of the independent effect of occupation on lung function in British coal miners. Occup Environ Med 1996;53:125-8.

8 Coggan D, Inskip H, Winter P, et al. Contrasting geographical distribution oggan $\mathrm{D}$, Inskip $\mathrm{H}$, Winter $\mathrm{P}$, et al. Contrasting geographical distribution
of mortality from pneumoconiosis and chronic bronchitis and emphysema of mortality from pneumoconiosis and chronic bronchitis

9 Soutar CA, Hurley JF, Gurr D. The relationship between dust exposure and lung function in miners and ex-miners. In: Sixth International Pneumoconiosis Conference, Bochum, 1983. Geneva, ILO, 1984: 390-6.

10 Soutar CA, Campbell S, Gurr D, et al. Important deficits of lung function in three modern colliery populations. Am Rev Respir Dis 1993;147:797-803. 